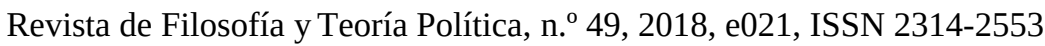

Universidad Nacional de La Plata.

Facultad de Humanidades y Ciencias de la Educación.

Departamento de Filosofía

\title{
La constitución del campo filosófico en La Plata y Tucumán: Un estudio comparado de grupos académicos entre la Reforma Universitaria y el primer peronismo (1920-1946)
}

\section{Clara Inés Ruvituso \\ Universidad Libre de Berlín, Argentina \\ clararuvituso@gmail.com}

\section{Paula Jimena Sosa}

CONICET, Argentina jimenasosa89@gmail.com

Cita sugerida: Ruvituso, C. I. y Sosa, P. J.(2018). La constitución del campo filosófico en La Plata y Tucumán: Un estudio comparado de grupos académicos entre la Reforma Universitaria y el primer peronismo (1920-1946). Revista de Filosofía y Teoría Política, (49), e021. https://doi.org/10.24215/23142553e021 


\section{La constitución del campo filosófico en La Plata y Tucumán: Un estudio comparado de grupos académicos entre la Reforma Universitaria y el primer peronismo}

(1920-1946)

Clara Inés Ruvituso

Universidad Libre de Berlin, Argentina

clararuvituso@gmail.com

Paula Jimena Sosa

CONICET, Argentina

jimenasosa89@gmail.com

\section{RESUMEN:}

En el presente trabajo nos proponemos comparar la constitución del campo filosófico en La Plata y Tucumán entre la Reforma Universitaria y el primer peronismo (1920-1946). El análisis se centra en los diferentes grupos académicos que disputaron los espacios y debates en cátedras y publicaciones durante la hegemonía reformista, y las rupturas y continuidades provocadas por las intervenciones universitarias en 1946 durante el primer gobierno de Juan D. Perón.

Palabras clave: Campo filosófico, La Plata, Tucumán, Reforma Universitaria, Primer peronismo.

\section{Abstract:}

We propose to compare the constitution of the philosophical field in La Plata and Tucumán between the University Reform and the first Peronism (1920-1946). The analysis focuses on the different academic groups that disputed the spaces and debates in chairs and publications during the reformist hegemony, and the ruptures and continuities caused by the university interventions in 1946, during the first government of Juan D. Perón.

KeYworDs: Philosophical Field, La Plata, Tucumán, University Reform, First Peronism.

\section{INTRODUCCIÓN}

La constitución de los estudios filosóficos en la Universidad Nacional de La Plata (UNLP) y en la Universidad Nacional de Tucumán (UNT), a lo largo del período de hegemonía de las élites reformistas en las universidades argentinas, se desarrolló en el marco de confluencias y entrecruzamientos de diversos grupos académicos en disputa. En La Plata, centro del movimiento reformista liderado por el médico y filósofo Alejandro Korn, los estudios filosóficos se consolidaron con el aporte de intelectuales porteños y locales, y en el marco de las disputas contra el positivismo. En la UNT, nacionalizada con el impulso del movimiento reformista en 1921, los estudios en humanidades, establecidos recién en 1938, nacieron reformados, y se consolidaron a partir de una extraordinaria confluencia de intelectuales humanistas locales, la migración intelectual reformista y antipositivista rioplatense, y el exilio de numerosos intelectuales europeos. Sobre la base de estas diferencias en la formación de los grupos académicos que confluyeron en ambos espacios, las intervenciones universitarias del primer gobierno de Juan D. Perón en 1946 tuvieron consecuencias muy dispares en ambas casas de estudio.

En el presente trabajo, nos proponemos comparar la constitución de los estudios filosóficos en La Plata y Tucumán entre la Reforma Universitaria y el primer peronismo (1920-1946), tomando en consideración los grupos académicos que disputaron sus espacios y debates en cátedras y publicaciones, y las rupturas y continuidades provocadas por los recambios docentes vinculados especialmente a las posiciones políticas de los actores. Esta investigación conjunta, sobre la base del trabajo de archivos e investigaciones previas, ${ }^{1}$ se concentra en el análisis de la constitución de los estudios filosóficos desde el marco político e institucional. 
Sostenemos que, en contextos políticos y sociales de fuertes intervenciones estatales en la vida universitaria, como fue el de la Argentina entre 1920 y 1946, resulta relevante tomar en cuenta los condicionamientos políticos que afectaron el funcionamiento y la vida de los académicos. Así, el concepto bourdiesiano de “campo" nos ayudará a pensar el ámbito académico y disciplinar filosófico desde una mirada que no nos condicione a una explicación interna de su constitución, ni a una exclusivamente contextual (Bourdieu, 1997). Tomando como referencia los grupos de profesores y profesoras que disputaron la constitución del campo, en este trabajo se analizan las tensiones entre autonomía y heteronomía, ${ }^{2}$ en un campo académico que suele considerarse -desde su propia lógica-, sin atender al contexto (Bourdieu, 1991). Este abordaje socio-histórico del campo filosófico pretende ser un punto de partida para posteriores indagaciones sobre la relación de los contextos políticos y la producción de filosofía en Argentina.

En el primer apartado se analizan los diferentes grupos académicos que configuraron el campo filosófico en la UNLP y la UNT, durante el período de hegemonía de los grupos reformistas en la conducción de ambas casas de estudio (1920-1946). En ambos casos, el desarrollo de la disciplina filosófica en el ámbito académico se vinculó con la crítica y la superación del positivismo, y con contextos de lucha por la apertura y la participación plural en el gobierno universitario, y por la nacionalización de universidades provinciales. Para la presente reconstrucción socio-histórica de las posiciones de los filósofos, dentro de los campos platense y tucumano, proponemos la división analítica de los actores en diversos grupos académicos que abarcan la influencia de los locales, la migración entre ciudades y provincias y el exilio europeo.

\section{LA CONSTITUCIÓN DEL CAMPO FILOSÓFICO EN LA UNLP: ENTRE VISITANTES Y LOCALES}

La formación de los estudios filosóficos en la UNLP comenzó a desarrollarse a partir de su nacionalización en 1906, con la fundación de la sección de Pedagogía, y en 1909 con la de Filosofía, Historia y Letras que estuvo, hasta 1914, bajo la dependencia de la Facultad de Ciencias Jurídicas y Sociales. La nueva Universidad, ideada por Joaquín V. González, debía construirse en base a un proyecto modernizador inspirado en el modelo inglés de perfil cientificista y moderno, en contraposición con el tradicionalismo clerical de la Universidad de Córdoba, y el perfil profesional de la Universidad napoleónica francesa, que prevalecía en la Universidad de Buenos Aires (UBA). Hasta 1920, las humanidades contaron con pocas cátedras en actividad, y junto a la sección de Pedagogía, se fundieron para constituir la Facultad de Ciencias de la Educación en 1914. Durante el primer decanato ejercido por el pedagogo Víctor Mercante entre 1914 y 1920, la nueva Facultad se especializó en los estudios pedagógicos, prevalenciendo la orientación positivista, mientras que las disciplinas de la sección Historia, Filosofía y Letras tuvieron menor desarrollo (Barba, 2005). La profundización y consolidación de las humanidades, en la nueva unidad académica, tuvo lugar en 1920, junto con la reforma de los estatutos, cuando la Facultad de Ciencias de la Educación pasó a llamarse Facultad de Humanidades y Ciencias de la Educación (FHyCE) y se modificaron los planes de estudio, "concediendo igual importancia a los estudios pedagógicos que a las disciplinas humanistas y desarrollando paralelamente ambas ramas del saber" (Nazar Anchorena, 1927, p. 299). Las críticas de muchos de los reformistas al original proyecto positivista y utilitario, destinado a las humanidades, acompañaron los cambios institucionales implementados junto a la Reforma, y comenzaron a difundir nuevos perfiles de enseñanza en las cátedras. En la filosofía, el antipositivismo comenzó a perfilar una formación que pretendía no responder a los ideales positivistas de utilidad y aplicabilidad del saber, sino a una concepción "libre", "crítica" y "especulativa" del pensamiento, necesaria para el desarrollo de lo que sus principales precursores -como Alejandro Korn y Coriolano Alberini- designaban como una verdadera filosofía. $^{3}$

Hasta mediados de la década del cincuenta, la enseñanza de la filosofía estuvo ligada a las ciencias de la educación. Desde 1920, los títulos que expendía la Facultad en esa área era "Profesorado de enseñanza secundaria, normal y especial en Filosofía y Ciencias de la Educación” y "Doctorado en Filosofía y Ciencias de la Educación”. En la formación de los filósofos de la FHyCE abundaron las asignaturas pedagógicas: en 1926, 
el profesorado estaba constituido por 20 materias, de las cuales 7 estaban ligadas a las ciencias de la educación (Biología, Anatomía y Fisiología del Sistema Nervioso, Psicopedagogía y Práctica de Laboratorio, Higiene Escolar, Lectura y Comentario de Textos Pedagógicos, Didáctica General, Legislación Escolar argentina y comparada, Metodología Especial y Práctica de la Enseñanza); 8 eran materias específicamente filosóficas (Introducción a la Filosofía, Lógica, Historia de la Filosofía, Ética, Estética, Gnoseología y Metafísica, y Lectura y Comentario de Textos Filosóficos y Seminario). Los otros 5 cursos correspondían a Composición y Gramática, Latín, Historia Argentina, Antropología (en otra Facultad) y Sociología y una materia que, a lo largo de los años, se desarrolló en un territorio fronterizo de pedagogos y filósofos: Psicología. ${ }^{4}$ Las modificaciones de los planes de estudios impulsados por el decano Ricardo Levene en 1926 desarrollaron las materias de los doctorados. El doctorado en "Filosofía y Ciencias de la Educación" se constituyó de cuatro materias: Filosofía Contemporánea, Filosofía de la Educación, Historia de las Religiones y Problemas de las Ciencias de la Naturaleza. En 1934, los estudios filosóficos ganaron más autonomía gracias a la creación de un "Centro de Estudios Filosófico", formado por profesores, diplomados y estudiantes, con carácter de adscripto a la Facultad (Castiñeiras, 1985). Asimismo, el carácter de las publicaciones filosóficas que se editaron en la FHyCE, entre 1920 y 1946, a través de la revista "Humanidades", la colección "Biblioteca de Humanidades" y revistas estudiantiles, evidenciaron que la filosofía estaba desarrollando un camino cada vez más autónomo y especializado. ${ }^{5}$ En ese camino de creciente profesionalización y autonomía, que Francisco Romero caracterizó como "normalización”, las lecturas de Bergson, Kant, la fenomenología y el existencialismo alemanes, fomentadas por la mediación española liderada por José Ortega y Gasset, así como también los viajes de formación en Alemania, constituyeron un campo receptor de enorme productividad.

Si bien en el comienzo de la constitución de la enseñanza filosófica en la FHyCE, algunas de las cátedras estaban a cargo de profesores que no tenían formación específicamente filosófica, como también ocurría en la FFyL de la UBA, esta situación se fue corrigiendo rápidamente. ${ }^{6}$ Alfredo Ferreira (1862-1938), titular de Ética, era un abogado y pedagogo correntino, y Alejandro Korn (1860-1936), médico psiquiatra y filósofo autodidacta, dictaba Historia de la Filosofía. Para 1930 estos dos profesores, nacidos en la década de 1860, ya se habían retirado de la enseñanza de filosofía: Alfredo Ferreira se jubiló en 1924, y Alejandro Korn, en 1930. Si tomamos en cuenta todo el período transcurrido entre 1920 y 1946, de los profesores formados en filosofía que se desempeñaron en la FHyCE podemos perfilar dos grupos académicos, los "visitantes" y los "locales", diferenciados por la generación a la que pertenecieron y el lugar de formación.

El grupo de profesores "visitantes" tuvo un protagonismo importante como primer formador de los estudios filosóficos y de discípulos en la FHyCE. Fueron profesores que, salvo por el mencionado caso de Alejandro Korn (formado en medicina) y de Tomás Casares (que era abogado), en su mayoría pertenecían a una generación nacida entre 1886 y 1896, y que se había formado en filosofía en la FFyL de Buenos Aires o en Europa. Coriolano Alberini (1886-1960), egresado de Filosofía y Letras de la UBA en 1911 y figura clave en la constitución de la filosofía en Buenos Aires, se desempeñó en La Plata como titular en "Introducción a la Filosofía” entre 1921 y 1946, y en "Gnoseología y Metafísica” entre 1922 y 1943. Alfredo Franceschi (1891-1942), egresado de filosofía de la UBA, fue titular de "Lógica” entre 1921 y 1942. Enrique Mouchet (1886-1977), médico y Doctor en filosofía de la UBA, se desempeñó en "Psicología" desde 1922 a 1946. Sus posiciones positivistas lo obligaron a renunciar a la cátedra de "Filosofía contemporánea" en 1929. El católico Tomás Casares (1895-1976), abogado egresado de la UBA, ocupó desde 1926 suplencias en varias asignaturas de Filosofía, y en 1935 fue nombrado titular de "Ética", año en el que presentó su renuncia. Tres profesores posicionaron la creciente recepción alemana en la UNLP: Luis Juan Guerrero (1896-1957), doctorado en Filosofía por la Universidad de Zúrich, comenzó a ocupar suplencias de "Lógica" y "Gnoseología y Metafísica" en 1926; fue profesor suplente de "Estética" desde 1929, y luego titular en esa disciplina desde 1935 hasta su separación en 1946. Francisco Romero (1891-1962), de carrera militar y formado en Filosofía en la UBA (aunque sin obtener título), enseñó "Filosofía Contemporánea" desde 
1931 hasta 1946. Carlos Astrada (1894-1970), quien se había formado en Alemania entre 1927 y 1932, dictó "Ética" desde 1937 hasta 1948.

El grupo de "locales" se consolidó en base a aquellos profesores que se habían formado en la FHyCE, y que comenzaron a ocupar cargos suplentes, interinos o titulares (de materias dejadas vacantes por licencias, renuncias o jubilaciones del grupo de formadores), o bien gracias a la creación de nuevas asignaturas. Este grupo pertenecía a una generación nacida entre fines e inicios del siglo XX y, en su gran mayoría, habían realizado sus estudios secundarios en diferentes promociones del Colegio Nacional de La Plata. ${ }^{7}$ Los primeros egresados de la FHyCE que integraron este grupo fueron Ernesto Figueroa, Sansón Raskovsky y José A. Rodríguez Cometta; más tarde se sumaron Eugenio Pucciarelli, Segundo Tri, Francisco Maffei y Emilio Estiú. Ernesto Figueroa (aprox. 1896-1956) comenzó su carrera docente en 1921 como Jefe del "Seminario de filosofía", y como encargado de "Lectura y comentarios de textos filosóficos", cuando todavía era un estudiante de Filosofía en la FHyCE. En 1932 logró la titularidad como Jefe del "Seminario de filosofía” y de las cátedras de "Historia de la filosofía" y de "Psicología", posiciones a las que renunció en 1946. Por su parte, Sansón Raskovsky comenzó a ocupar cargos suplentes en "Lógica” y "Gnoseología y Metafísica” de 1926 a 1944, año de su renuncia. José A. Rodríguez Cometta (1900-1976) asumió cargos como Profesor interino (en "Lectura y comentario de textos" y luego en "Gnoseología y Metafísica") desde 1929 hasta su separación en 1946. Años más tarde, iniciaron sus carreras otros graduados de la casa: Francisco Maffei (1903-1975) en 1937, como adscripto de "Historia de la Filosofía"; Eugenio Pucciarelli (1907-1995) en 1933, como suplente de "Gnoseología y Metafísica"; Segundo Tri en 1944, como ayudante del "Seminario de filosofía”, y Emilio Estiú (1914-1985) en 1945, como adscripto de "Filosofía contemporánea". La mayoría de estos profesores se había formado en el círculo intelectual y discipular creado alrededor de la figura de Alejandro Korn. Entre ellos se encontraban Francisco Romero, Ernesto Figueroa, Segundo Tri, José A. Rodríguez Cometta, Francisco Maffei y Eugenio Pucciarelli.

En los años veinte, todos ellos, desde diferentes sectores, apoyaron activamente la Reforma Universitaria. Se habían formado en un clima intelectual antipositivista, renovador de la filosofía, especialmente en base a la influencia de Bergson y del neokantismo. Excepto Casares, ninguno de los profesores que formaron el plantel docente de Filosofía, en la FHyCE, puede considerarse anti-reformista en sus inicios; sin embargo, en 1946 asumen posiciones políticas muy diferentes con respecto a la intervención de la Universidad por parte del gobierno de Juan D. Perón.

\section{EL CAMPO FILOSÓFICO TUCUMANO Y UNA EXTRAORDINARIA CONFLUENCIA}

La Universidad de Tucumán se creó en 1912, siguiendo el modelo francés, y se nacionalizó en 1921 por obra de un grupo denominado "ncleo fundador", 8 entre los cuales se encontraban varios miembros de la élite provincial ligados a la industria azucarera. En la ardua lucha por alcanzar esa nacionalización, resultaron claves las gestiones de Juan B. Terán, así como también la actuación del movimiento estudiantil dirigido por el presidente de la Federación Universitaria Argentina, Gabriel del Mazo, quien llegó a reunirse personalmente con el presidente Hipólito Irigoyen para solicitar ese traspaso.

A pesar de la fuerte raigambre humanista de sus fundadores, durante los primeros años de la Universidad, la promoción del conocimiento estuvo vinculada con el fortalecimiento de la industria azucarera. La formación de los estudios humanísticos en la UNT comenzó a desarrollarse recién a partir de 1936 con la fundación del Departamento de Filosofía, Historia, Pedagogía, Letras e Idiomas, y en 1939 -durante el Rectorado de líder reformista Julio Prebisch (1937-1940) - se convirtió en Facultad de Filosofía y Letras (FFyL). ${ }^{9}$ Entre los objetivos iniciales del Departamento de Filosofía, se encontraba el fomentar el vínculo con lo local:

a) integrar la cultura universitaria de los estudiantes de las Facultades que componen la universidad; b) Organizar y dirigir la extensión universitaria, c) estudiar la naturaleza, la historia, la sociedad y la economía del norte y noroeste argentino y 
aconsejar las soluciones regionales que sus problemas prácticos planteen, y d) formar el profesorado de enseñanza secundaria y normal (Universidad Nacional de Tucumán, 1914-1939, Violetto, Tucumán, 1939).

Las dos carreras que formaban parte de los primeros años de estudios filosóficos académicos fueron "Filosofía y Letras" y "Filosofía y Pedagogía". Ambas se componían de 23 materias. Sin embargo, la distribución presentaba claras diferencias. En cuanto a las materias vinculadas a las Ciencias de la educación, la primera sólo tenía dos ("Pedagogía general” y "Metodología y práctica pedagógica”), mientras que la segunda, cuatro "Pedagogía general", "Metodología y práctica pedagógica", "Historia de la educación" y "Legislación". Del área de Psicología, la primera carrera ligada a las letras tenía una materia en el primer año, mientras la segunda tres ("Psicología", "Psicología de la niñez y adolescencia" y "Psicología aplicada a la pedagogía"). En cuanto a la formación estrictamente filosófica, ambas carreras tenían siete materias idénticas: "Introducción a la Filosofía”, "Gnoseología y Metafísica", "Lógica”, dos niveles de "Historias de la Filosofía”, "Ética” y "Estética". La primera tenía cinco materias de idiomas (tres años de Latín y dos de idiomas modernos); en cambio, la segunda sólo contaba con dos años de cada idioma. Ambas carreras compartieron tres materias idénticas del área de historia: dos "Historias universales" y un año de "Historia argentina del siglo XIX". En cuanto a las materias estrictamente filosóficas, éstas se mantuvieron idénticas hasta 1945, a pesar de varias transformaciones de los planes de estudio.

Si se toma en cuenta el arco temporal que va de 1937 a 1946, de los profesores y pensadores que intervinieron en la constitución del campo, desempeñándose dentro y fuera del Departamento y luego en la FFyL, podemos establecer tres grupos que se distinguen por sus orígenes, por su formación y por la generación a la que pertenecieron. ${ }^{10}$

La generación de "figuras locales" se compuso de intelectuales que conformaron el núcleo fundador de la Universidad. Este grupo no se caracterizó por participar en las cátedras, sino por gestionar e impulsar la consolidación institucional de la Filosofía en el campo académico. Entre ellos, se encontraban intelectuales nacidos entre 1873 y 1898, y formados en la UBA, especialmente en Derecho. Ernesto Padilla (1873-1951) se graduó en esta última casa de estudios, y llevó adelante una carrera política como Legislador, Diputado nacional y Gobernador de la provincia. Si bien no ocupó cátedras, gestionó por la mediación de Alberto Rougés y Eugenio Pucciarelli, ante la Nación, la transformación del Departamento de Filosofía en Facultad de Filosofía y Letras (Martínez Zuccardi, 2012). Alberto Rougés (1880-1945), aunque fue egresado de la Facultad de Derecho de la UBA, su producción filosófica lo consolidó tempranamente dentro del núcleo reconocido como "fundador de la Filosofía en Argentina" (Romero, 1952; Vázquez, 1965). Promovió la creación de la UNT junto a institutos, sociedades y revistas. Ya creada la FFyL, dictó seminarios filosóficos y fue Rector por un brevísimo período, interrumpido por su muerte en 1945. Manuel Lizondo Borda (1889-1966), también formado en la UBA en la carrera de Derecho, se especializó en Historia. A diferencia de los demás, participó del primer plantel docente de la carrera de Filosofía, dando clases en la cátedra de "Historia argentina del siglo XIX". Otra figura significativa en el ámbito intelectual local fue Alfredo Coviello (1898-1943), periodista del diario La Gaceta. Durante sus estudios en Buenos Aires fue alumno de figuras como Korn y Alberini, y aunque no completó su formación para la obtención del título de Abogado, tuvo una intensa gestión en el ambiente cultural de la región. En el ámbito local, trazó amistad con figuras claves del campo intelectual como los ya mencionados Rougés y Padilla. Vinculado a "Sociedad Sarmiento", fundó en ese espacio la revista Sustancia, uno de los proyectos editoriales más significativos en torno a la disciplina filosófica en la región del noroeste argentino.

Los profesores "rioplatenses" provenían de la UBA y de la UNLP, y se distinguían del grupo de profesores extranjeros y locales por su tendencia a promover una perspectiva más especializada en la Filosofía. Este grupo estuvo conformado sobre todo por una generación nacida entre 1910 y 1917. Entre ellos, encontramos a Risieri Frondizi (1910-1985), recibido como profesor de Filosofía por el Instituto Nacional del Profesorado de Buenos Aires, y Doctorado en Filosofía por la Universidad de Harvard. Además de asumir la dirección del Departamento, en el período 1938-1939, en reemplazo de Manuel García Morente, dictó “Inglés” en 1937, 
el curso "Lectura y comentarios de textos" entre 1937 y 1938, "Lógica” entre 1938 y 1946, "Estética” entre 1940 y 1941, "Historia de la Filosofía" (primer curso) entre 1939 y 1946, y el "Seminario de Filosofía" 11 entre 1944 y 1946. ${ }^{12}$ Eugenio Pucciarelli (1907-1995), Profesor y Doctor en Filosofía por la UNLP, fue Decano de la FFyL tucumana (1940-1944) y Profesor de "Introducción a la Filosofía", "Psicología" y "Gnoseología y Metafísica”, entre 1938 y 1944. Aníbal Sánchez Reulet (1910-1998), también egresado del Profesorado y del Doctorado en Filosofía (UNLP), ocupó la cátedra de "Psicología de la Niñez y adolescencia" entre 1939 y 1942, y luego fue eximido de su dictado para ocuparse del "Seminario de Filosofía", correspondiente al Doctorado en Filosofía. Paralelamente asumió las clases de "Historia de la Filosofía" (segundo curso) entre 1940 y 1946, de "Ética" entre 1940 y 1946, y en 1944 reemplazó a Pucciarelli en "Introducción a la Filosofía", y en el Decanato hasta 1946. Emilio Estiú (1914-1984), Profesor de Filosofía egresado de la UNLP, ocupó las cátedras de "Introducción a la Filosofía” y de "Estética" entre 1946 y 1949. Juan Adolfo Vázquez (1917-2010), otro Profesor de Filosofía recibido en la UNLP, primero dictó "Inglés” en el Colegio técnico dependiente de la Universidad, "Ética" e "Inglés" en la Escuela Sarmiento (también dependiente de la misma Universidad) durante 1941; al año siguiente ingresó en el plantel de la FFyL como Profesor de "Metodología de la enseñanza" y en "Historia de la educación”, reemplazando a Luzuriaga, y en "Gnoseología y Metafísica”, reemplazando a Pucciarelli hasta 1956.

No todos los profesores "extranjeros" que llegaron a Tucumán como resultado del exilio español, entre 1936 y 1946, fueron especialistas en el área de Filosofía. No obstante, debido a la importancia de los estudios de Letras e Historia en la carrera de Filosofía, tuvieron un enorme impacto en la formación filosófica. Esto permitió proyectar una comprensión de la disciplina que se caracterizó por su proximidad con otras áreas del campo de las Humanidades.

Este grupo, a la vez, puede considerarse como dividido en dos generaciones. La primera, de profesores nacidos entre 1877 y 1897, y que se formaron en diferentes disciplinas humanísticas en Europa. Este primer grupo estuvo integrado por algunos intelectuales destacados, provenientes de la formación intelectual liderada por José Ortega y Gasset, y formados en el Instituto Libre de Enseñanza (ILE). Manuel García Morente (1886-1942), Licenciado en Letras en la Universidad de Burdeos en 1905, llegó a la Argentina como exiliado republicano gracias a la intervención de Alberini. Era un intelectual especialista en filosofía alemana y destacado como traductor de Kant. Arribó a Tucumán con la misión de fundar el Departamento de Filosofía, y ocupó las cátedras de "Introducción a la Filosofía", "Psicología", "Metafísica y Gnoseología", y la dirección del Departamento de Filosofía entre 1937 y $1938 .{ }^{13}$ Lorenzo Luzuriaga (1889-1959), formado en el Magisterio de Madrid, en la Escuela Superior de Magisterio y en el ILE ocupó las cátedras de "Pedagogía”, "Historia de la Educación" y "Didáctica", así como también se desempeñó como Vicedecano de la Facultad hasta 1944, momento en el cual renunció a sus cargos en solidaridad con los docentes desplazados de sus cargos durante las intervenciones de Santiago de Estrada en 1943. María Luisa Navarro (1890-1947), formada en la Asociación para la Enseñanza de la Mujer y en la Escuela de Estudios Superiores de Magisterio, en Madrid, ingresó en 1939 y se retiró en 1943, ocupando la cátedra de "Metodología de la enseñanza". Clemente Hernando Balmori (1894-1966), formado en Filosofía y Letras en la Universidad Central de Madrid, se integró a la Universidad tucumana en las cátedras de "Latín I" y "II" en 1939, y se retiró en 1943. El italiano Benvenuto Aronne Terracini (1886-1968), formado en Lengua y Literatura en la Universidad de Turín, ingresó en 1940, ocupando la cátedra de "Lingüística" y los seminarios de Letras del Doctorado, retirándose de forma definitiva en 1947.

En segundo lugar, encontramos una generación posterior, integrada por los nacidos entre 1902 y 1914. Formado en Francia como Agrégé de Grammaire, Pierre Paul Hamelka (1902-?) dio clases de "Literatura francesa II", de "Latín” y de "Lengua y Cultura Francesas" entre 1938 y 1944. ${ }^{14}$ Jack Rush (1905-1978) se desempeñó entre 1939 y 1969, ocupando los cursos de "Lengua y cultura inglesas". Roger Labrousse (1908-1956), formado en Derecho y Letras en la Universidad de la Sorbonne, y egresado de la Escuela Libre de Ciencias Políticas, fue contratado en 1943 para dictar las cátedras de "Latín", "Literatura de Francia II", 
“Historia de Francia I” y “Francés” (Vanella, 2008), y en 1945 tomó las cátedras de "Historia universal II” e "Historia de las instituciones" de forma interina; luego fue designado titular de "Historia de las Instituciones" hasta 1953, año en que fue dejado cesante (Nader, 1999). Renato Treves (1907-1992), formado en Derecho y Doctor en Jurisprudencia por la Universidad de Turín, ocupó la cátedra de “Sociología” ${ }^{15}$ desde 1939 hasta su cesantía, en enero de 1944, y luego se reincorporó, gracias a la intervención de Sánchez Reulet, desde abril de 1944, manteniéndose en el cargo hasta 1949.

En Tucumán, como en otros espacios académicos, la consolidación de los estudios filosóficos estuvo atravesada por la tensión entre la especialización y la tendencia a disolver los límites disciplinares. Los partidarios de la primera posición fueron en general profesores egresados de la UBA, donde se dictaba Filosofía como carrera única, y de la UNLP, donde la disciplina filosófica estaba más unida a la Pedagogía, pero había ganado creciente autonomía. En cambio, la perspectiva de la Filosofía como área que convive con otras humanidades, tuvo su sostén gracias a la presencia de profesores extranjeros como Manuel García Morente, Rodolfo Mondolfo, Roger Labrousse y Elisabeth Goguel, que estaban formados en Humanidades y no respondían al ideario de especialización que se había difundido en la UBA y la UNLP. Asimismo, ya antes de la fundación de la FFyL, figuras locales como Alfredo Coviello, Alberto Rougés y Francisco Padilla alentaron el desarrollo de la Filosofía en espacios no-universitarios, como las bibliotecas públicas y la "Sociedad Sarmiento". ${ }^{16}$

\section{LOS ESTUDIOS FILOSÓFICOS TUCUMANOS Y PLATENSES FRENTE AL PERONISMO: RUPTURAS Y CONTINUIDADES}

Los estudios de historia intelectual que abordaron el impacto del peronismo en el ámbito académico coincidieron en una visión del período iniciado con la revolución militar de 1943 (y el triunfo electoral de Juan D. Perón en 1946), hasta 1955, como un momento de ruptura con el reformismo universitario vigente desde 1918, en base a la intervención en las universidades, a las consecuentes renuncias y cesantías de profesores y alumnos contrarios a las políticas oficiales, y al dogmatismo y el control ideológico del cuerpo docente y las autoridades académicas (Halperín Donghi, 1962; Magnone y Warley, 1984; Neiburg, 1998; Pronko, 2000; Sigal, 2002; Terán, 2009). Varios autores destacaron la entrada del nacionalismo católico a las universidades como uno de los rasgos centrales de la política educativa peronista, y enfatizaron sus efectos negativos en las Humanidades. Estas perspectivas que enfatizan el quiebre fueron matizadas por estudios historiográficos enfocados en el impacto que el peronismo suscitó en el ámbito de disciplinas y facultades particulares (Buchbinder, 1997; Soprano, 2009; Ruvituso, 2015). En el segundo apartado, daremos cuenta de las rupturas y continuidades en las trayectorias académicas de los profesores de Filosofía en Tucumán y La Plata, analizando comparativamente cómo se fueron estructurando los recambios docentes en cada de una de las cátedras.

\section{LOS RECAMBIOS EN UNLP Y LA HEGEMONÍA CATÓLICA}

La intervención de la UNLP en 1946, por parte del gobierno del presidente Juan D. Perón, motivó el recambio docente en varias asignaturas filosóficas. Salvo en el caso de Alberini, ${ }^{17}$ los otros cinco profesores de Filosofía que se retiraron en 1946 estaban vinculados al grupo académico reformista que había liderado Alejandro Korn, y se opusieron a las intervenciones. ${ }^{18}$ Ernesto Figueroa, que había asumido el Decanato de la FHyCE en 1945 con una fuerte impronta reformista, renunció a todos sus cargos y se retiró de la vida académica en 1946. Con la salida de Figueroa, las cátedras de "Psicología", "Historia de la Filosofía" (Moderna y Antigua y Medieval) y la dirección del "Seminario de filosofía” quedaron vacantes. 
El principal discípulo de Korn, Francisco Romero, fue una de las figuras del campo filosófico más comprometidas con la oposición al movimiento peronista. Renunció a las cátedras de "Historia de la filosofía contemporánea" y "Lógica” de la UNLP, junto a las que tenía en la UBA, en 1946. Uno de los jóvenes reformistas ligados en La Plata a Korn era José A. Rodríguez Cometta, quien fue separado de su cargo de suplente interino de "Gnoseología y Metafísica" y de Director del "Preseminario de filosofía" en 1946. También Segundo Tri, quien se desempeñaba como ayudante en el "Seminario de filosofía” y en "Metodología y práctica de la enseñanza", fue separado de sus cargos en 1946. Luis Juan Guerrero fue expulsado de la FHyCE en 1946, por adherirse a la huelga declarada por los estudiantes, pero logró retener sus cargos en la UBA. Finalmente, existieron dos cátedras, en donde el recambio docente de 1946 no redundó en renuncias o exoneraciones de sus profesores: "Lectura y comentario de textos filosóficos" continuó bajo la dirección de Francisco Maffei, y la cátedra de "Ética" siguió en las manos de Carlos Astrada hasta 1948. ${ }^{19}$

Las renuncias y exoneraciones de profesores en 1946 modificaron tanto el plantel docente del Profesorado y del Doctorado en "Filosofía y Ciencias de la Educación", así como también algunas orientaciones de sus cátedras, al incorporar presbíteros y representantes de la Filosofía escolástica y neotomista a la enseñanza. La figura central del nuevo período en La Plata fue el presbítero Octavio N. Derisi, quien asumió la titularidad de la cátedra de "Gnoseología y Metafísica", dejada vacante por la renuncia de Rodríguez Cometta. Derisi asumió en 1948 la dirección del flamante Instituto de Filosofía y la Revista de Filosofía en 1950. Asimismo, la cátedra de "Psicología", dejada vacante por Mouchet, fue ocupada interinamente por el presbítero Leonardo Castellani, y en 1947 el nuevo titular concursado fue Luis Felipe García de Onrubía. En mayo de 1947, Héctor G. Llambías ganó el concurso de la cátedra de "Lógica", dejada vacante por Romero. La renuncia de Figueroa en 1946 motivó que Benito Raffo Magnasco fuera designado titular de "Historia de la filosofía antigua y medieval”. La exoneración de Guerrero en 1946 motivó la entrada de Jorge H. Attwell de Veyga como titular de "Estética". En el "Seminario de filosofía", la renuncia de Ernesto Figueroa a la dirección del curso fue resuelta con el nombramiento de Horacio Shindler en 1946, y luego por Viterman E. Centurión. La renuncia de este último motivó la designación de Martiniano Juanes como titular. Algunos jóvenes egresados de la UBA y de la UNLP, que no respondían ni al tomismo ni al anti-reformismo, también accedieron a cargos titulares dejados libres por sus formadores. La renuncia de Figueroa en 1946 motivó que Rodolfo Agoglia, profesor de la UBA, fuera designado titular de "Historia de la filosofía moderna" en 1947. Pucciarelli asumió la cátedra de "Introducción a la filosofía" ante la jubilación de Alberini, hasta ser designado titular en 1947. Frente a la renuncia de Romero en 1946, la cátedra de "Filosofía contemporánea" (que pasó a denominarse "Historia de la filosofía contemporánea"), fue ocupada por Emilio Estiú, quien se había desempeñado como adscripto.

\section{La Facultad de Filosofía y Letras tucumana: Vaivenes y entrecruzamientos}

A diferencia de La Plata, en Tucumán los recambios docentes provocados por las intervenciones del primer gobierno peronista no implicaron una hegemonía de sectores católicos. Si bien en 1944 ya se había producido una fuerte transformación de esa casa de estudios, por la renuncia de Pucciarelli, Luzuriaga y Navarro, ${ }^{20}$ las exoneraciones durante el primer peronismo en el área de Filosofía se limitaron a dos figuras: Aníbal Sánchez Reulet y Risieri Frondizi. Asimismo, la apertura de nuevas cátedras en el marco de los estudios humanísticos también favoreció la entrada de nuevos docentes. ${ }^{21}$

Aníbal Sánchez Reulet, quien había asumido el Decanato de la FFyL en 1945, fue exonerado de sus cargos el 14 de noviembre de 1946, dejando vacantes el Decanato y las cátedras de "Historia de la filosofía" (segundo curso) y de "Ética". ${ }^{22}$ Asimismo, Risieri Frondizi fue desplazado de sus cargos en noviembre de 1946 a través del interventor interino Manuel García Soriano, dejando vacantes las cátedras de "Lógica", "Historia de la 
filosofía” y el Seminario de filosofía. ${ }^{23}$ Por su parte, Emilio Estiú se reincorporó a la UNLP en 1947, de modo que "Estética" e "Introducción a la filosofía" también quedaron vacantes.

En sus lugares ingresaron profesores y profesoras que en general carecían de un perfil católico u oficialista. La profesora francesa Elisabeth Goguel asumió las cátedras de "Historia de la filosofía" y de "Ética", anteriormente ocupadas por Sánchez Reulet, y fue designada ad honorem para "Historia de las ciencias". Rodolfo Mondolfo (1877-1976), Doctorado en Filosofía por la Universidad de Florencia, y exiliado en Argentina desde 1938, ocupó en 1948 la cátedra de "Historia de la filosofía" (primer curso), anteriormente ocupada por Frondizi, y la dirección del Instituto de Filosofía hasta 1951, cuando renunció al cargo por motivos personales. ${ }^{24}$ Jorge Hernán Zucchi (1917-2000), egresado de Filosofía y Letras de la UBA, ingresó en 1948 a la cátedra de "Historia de la filosofía" hasta 1955, y luego a "Filosofía antigua" durante el período que va de 1953 a 1980. María Eugenia Valentié, egresada de la FFyL de la UNT en 1942, se incorporó al plantel en 1948, como asociada a la cátedra de "Metafísica y Gnoseología”, y en 1956 sucedió a Vázquez en esta cátedra. Luis Farré, quien contaba con estudios efectuados en Barcelona y luego con el Profesorado en Filosofía en la UNC, se sumó al plantel docente, haciéndose cargo de las cátedras de "Historia de la filosofía" (primer curso) después de 1951, y de "Estética", sucediendo a Estiú entre 1948 y1956. Entre los intelectuales católicos que se incorporaron al plantel docente, encontramos a Manuel Gonzalo Casas, ${ }^{25}$ con formación de base tomista, quien asumió la conducción de "Introducción a la filosofía" en 1952, y a Diego Pró, ${ }^{26}$ que se desempeñó entre 1948 y 1955 en la cátedra de "Lógica", además de dirigir el Instituto de Filosofía entre 1951 y 1955, anteriormente a cargo de Mondolfo. Además asumió como Decano de la FFyL, y luego como Rector en mayo de 1954 durante el breve período de 4 meses. Luego en 1955, con la interrupción provocada por la denominada "Revolución Libertadora", quedó cesante. ${ }^{27}$

De acuerdo con este mapa de ingresos y salidas de la FFyL tucumana, el primer peronismo impactó en la constitución del plantel, no por un gran número de cesantías, sino por los lugares que se dejaron vacantes debido al reacomodamiento general que implicaron las intervenciones a nivel nacional, de modo que es posible pensar este proceso no bajo la idea de ruptura y decadencia académica e institucional. Además, los recambios del período posibilitaron la profundización de tendencias ya existentes y la innovación, pues el perfil internacional, la confluencia de diversas posiciones políticas (incluyendo antiperonistas), y la entrada de mujeres, entre otros elementos, marcaron el perfil de la enseñanza filosófica en Tucumán.

\section{CONCLUSIONES: PENSAR LA FILOSOFÍA EN SU CONTEXTO}

La ciudad de La Plata fue uno de los escenarios donde la lucha del reformismismo fue más radical. Allí, Alejandro Korn, como líder reformista y "Maestro de la Juventud", se consolidó como una figura política rectora de enorme influencia. En Buenos Aires, la centralidad de Coriolano Alberini, con una fuerte impronta antipositivista, impulsó un ala crecientemente conservadora frente al reformismo de izquierda de la capital provincial. A pesar de estas diferencias, el período de hegemonía reformista, que puede extenderse aproximadamente entre 1920 y 1946, se caracterizó, en ambas ciudades, por el esfuerzo en favor de consolidar estudios especializados, primero de fuerte impronta bergsoniana y kantiana, incorporando más tarde la fenomenología y el existencialismo alemanes. En la recepción alemana del campo filosófico rioplatense tuvieron un rol central Francisco Romero, Luis Juan Guerrero y Carlos Astrada, quienes consolidaron un perfil de profesionalización de la actividad filosófica universitaria, pero con confrontaciones en el plano político. A diferencia de La Plata y de Buenos Aires, donde la constitución de la disciplina coincidió con la Reforma Universitaria y con una bsqueda de refutación del positivismo, la Facultad de Filosofía y Letras de Tucumán nació reformada, de tal manera que, en Tucumán, los estudios humanísticos se desarrollaron con relativa independencia respecto de las luchas antipositivistas. Allí, la filosofía se desplegó en una triple confluencia: los intelectuales "locales" (humanistas tucumanos ligados a la fundación de la Universidad, que 
promovieron la apertura de facultades, institutos y departamentos, así como también fomentaron proyectos editoriales con impronta antipositivista); los profesores extranjeros (que habían arribado al país debido a la derrota republicana en la Guerra Civil Española, y que habían sufrido persecuciones durante la Segunda Guerra Mundial), y los jóvenes profesores de filosofía, egresados de la UNLP y de la UBA.

En la constitución de las carreras de Filosofía que ofrecía la nueva Facultad tucumana, puede observarse la confluencia de estos tres grupos y de sus respectivos idearios, desde el promovido por figuras locales formadas en Buenos Aires, bajo el impacto de la crisis del positivismo, hasta la perspectiva filosófica de los extranjeros exiliados, marcada por la búsqueda de recuperar un humanismo universal, preservando la sensibilidad ante el tratamiento filosófico de las religiones.

Si en la UNLP, el tono crecientemente germanista fue interrumpido -en parte- por las intervenciones universitarias del primer peronismo, provocando un enorme recambio docente y la entrada de numerosos filósofos ligados al neotomismo, en la UNT la intervención no tuvo el mismo impacto conservador. Muchas de las cátedras tucumanas fueron ocupadas por intelectuales antifascistas, opositores y también católicos (e incluso por mujeres), profundizando el perfil internacional ya existente y la convergencia de grupos académicos muy diversos. En ambas casas de estudios las revistas filosóficas que se fundaron, en esta etapa, evidenciaron los cambios - pero también las continuidades- que se habían desarrollado. La revista Notas y estudios de filosofía, fundada en 1949, editó 17 números hasta 1954, bajo la dirección de Juan Adolfo Vázquez, evidenciando un momento de circulación internacional inédita de las ideas filosóficas en un territorio provincial, que podría ser considerado por entonces como periférico. En La Plata, la Revista de Filosofía, fundada en 1950 bajo la dirección de Octavio N. Derisi, si bien de perfil neotomista, convivió con las tendencias de la filosofía germánica, moderna y contemporánea, que se habían desarrollado en el período anterior. La revista platense también mostró un esfuerzo creciente de profesionalización e internacionalización.

Como advertimos en este trabajo comparativo, la constitución de los estudios filosóficos, en La Plata y en Tucumán, estuvo fuertemente condicionada por los diferentes contextos políticos locales, nacionales e internacionales. Si bien ambos espacios provinciales mostraron notables diferencias en la relación entre autonomía y heteronomía, la mayoría de los actores involucrados en su formación vio interrumpida más de una vez su trayectoria académica como producto de los vaivenes de la política nacional y/o internacional. Estas consideraciones socio-políticas buscan poner en evidencia la importancia de incorporar el análisis de las condiciones de producción, para repensar la producción filosófica.

\section{RefEREnCias}

Barba, E. (2005). La Universidad Nacional de La Plata en el centenario de su nacionalización, La Plata, UNLP.

Bourdieu, P. (1991). La ontología política de Martin Heidegger, Barcelona, Paidós.

Bourdieu, P. (1997). Los usos sociales de la ciencia, Buenos Aires, Nueva Visión.

Buchbinder, P. (1997). Historia de la Facultad de Filosofia y Letras. Universidad Nacional de Buenos Aires, Buenos Aires, Eudeba.

Buchbinder, P. (2005). Historia de las universidades argentinas, Buenos Aires, Sudamericana.

Castiñeiras, J. (1985). Historia de la Universidad de La Plata Tomo II, La Plata, UNLP.

Coviello, A. (1942). Una página de historia en la naciente filosofía argentina y otros ensayos, Tucumán, Septentrión.

David, G. (2004). Carlos Astrada. La filosofía argentina, Buenos Aires, El cielo por asalto.

Garrido Biazzo, B. H. (1999). La Facultad de Filosofia y Letras de la Universidad Nacional de Tucumán, Tucumán, Facultad de Filosofía y Letras.

Halperín Donghi, T. (1962). Historia de la Universidad de Buenos Aires, Buenos Aires, Eudeba.

Magnone, Carlos y Warley, Jorge (1984). Universidad y peronismo (1946-1955), Buenos Aires, CEAL. 
Martínez Zuccardi, S. (2012). Literatura, vida intelectual y revistas culturales en Tucumán (1904-1944), Buenos Aires, Corregidor.

Nader, R., comp. (1999). Las voces de la memoria, Tucumán, Facultad de Filosofía y Letras.

Naessens, H., y Santillán, A., comp. (1999). Testimonios de vida universitaria, Tucumán, Facultad de Filosofía y Letras.

Nazar Anchorena, B. (1927), La Universidad Nacional de La Plata, La Plata, UNLP.

Neiburg, F. (1998). Los intelectuales y la invención del peronismo. Estudios de antropología socialy cultural, Buenos Aires, Alianza.

Pró, D. (1960). Coriolano Alberini, Buenos Aires, López.

Pronko, M. (2000). El Peronismo en la Universidad, Buenos Aires, Eudeba.

Romero, F. (1952). Sobre la filosofía en América, Buenos Aires, Raigal.

Ruvituso, C. (2008). Política universitaria y campo académico. Un estudio centrado en la trayectoria del área de filosofía de la Facultad de Humanidades y Ciencias de la Educación de la Universidad Nacional de La Plata (1920-1946). Tesis de Licenciatura en Sociología. http://www.memoria.fahce.unlp.edu.ar/trab_eventos/ ev.6400/ev.6400.pd f

Ruvituso, C. (2015). Diálogos existenciales. La filosofía alemana en la Argentina peronista (1946-1955), Berlín / Madrid: Vervuert/Iberoamericana.

Schobinger, J. (1995). Humanismo siglo XX, San Juan, Fundación Universidad San Juan.

Sigal, S. (2002). "Intelectuales y peronismo". En J. C. Torre (dir.). Los años peronistas (1943-1955), Buenos Aires, Sudamericana, pp. 481-522.

Soprano, G. (2009). "Política, instituciones y trayectorias académicas en la universidad argentina. Antropólogos y antropología en la Universidad Nacional de La Plata entre las décadas de 1930 y 1960”. En: M. Marquina, C. Mazzola y G. Soprano (comps). Politicas, instituciones y protagonistas de la Universidad argentina, Buenos Aires, Prometeo, pp. 111-152.

Southwell, M. (2003). Psicología experimental y ciencias de la educación. Notas de historia y fundaciones, La Plata, EDULP.

Suayter Monneti, M. A. (2004). Los estudios humanisticos en la Universidad Nacional de Tucumán 1914-1945, Tucumán, Facultad de Filosofía y Letras.

Terán, O. (2008). Historia de las ideas en la Argentina. Diez lecciones iniciales, 1810-1980, Buenos Aires, Siglo XXI.

Vanella, L. (2008). El exilio europeo en la Universidad Nacional de Tucumán en las décadas de 1930 y 1940. Tesis para alcanzar el título de Doctora en Ciencias de la Educación. Universidad Nacional de Córdoba. https://rdu.unc. edu.ar/bitstream/handle/11086/1952/Tesis\%20Vanella.pdf;sequence=1.

Vázquez, J. A. (1965). Antología filosófica argentina del siglo XX. Buenos Aires, Eudeba.

Zarrilli, A., Gutierrez, T., y Graciano, O. (1998). Los estudios históricos en la Universidad Nacional de La Plata (1905-1990). Tradición, renovación y singularidad, Buenos Aires, Academia Nacional de la Historia.

\section{Notas}

1 Se trata de una elaboración comparada de las conclusiones presentes en la Tesina de licenciatura de Ruvituso (2008) y en su tesis doctoral (Ruvituso, 2015), y los trabajos presentados por Ruvituso y Sosa en el simposio "La filosofía en Argentina. Debates y prácticas en un campo académico periférico”, llevado a cabo el 13 de octubre de 2017 en la Universidad Sorbonne Nouvelle París-3.

2 El campo académico, al que hace referencia Pierre Bourdieu (1997), designa un espacio relativamente autónomo, un microcosmos provisto de leyes propias, con sus posiciones y luchas, pero también sometido a las leyes sociales del contexto más amplio. Cuanto más autónomo es un campo tiene más capacidad de refractar las coacciones o las demandas externas, como las que provienen del campo de la política, mientras que la heteronomía de un campo se muestra en el hecho de que los problemas exteriores se manifiestan directamente (o con mediaciones más débiles) en él.

3 A pesar del avance de las corrientes idealistas, el área de Ciencias de la educación y Psicopedagogía continuó con la influencia de la tradición de la psicología experimental trazada por Víctor Mercante y prolongada por su discípulo 
Alfredo Calcagno, quien reemplazó a Mercante como titular de la cátedra de Psicopedagogía y se desempeñó en el laboratorio, como fundamento del desarrollo científico y empírico de su área (Southwell, 2003). Sin embargo, la influencia de las nuevas corrientes humanistas y el hecho de que los estudios de filosofía estuvieran unidos a las Ciencias de la educación repercutieron en los estudios de psicología y psicopedagogía. Otras corrientes, como las del novencentismo antipositivista y el pensamiento evolucionista del filósofo francés Henri Bergson, difundidas por los profesores de filosofía Coriolano Alberini y Ernesto Figueroa, y por el médico Marcos Victoria, comenzaron a incidir en los estudios de la educación, así como las corrientes culturalistas y espiritualistas difundidas por otros profesores del área, como Juan E. Cassani, titular de Legislación Escolar, y Juan Mantovani, profesor interino de Filosofía de la Educación (Ruvituso, 2008).

4 En el área de Psicología, la disputa en torno a la orientación de la cátedra tuvo como correlato que, en 1929, el médico psiquiatra y profesor de filosofía Enrique Mouchet, de orientación positivista y reformista, renunciara a su cargo docente y que, en su lugar, fuera designado Ernesto Figueroa, profesor de filosofía de orientación antipositivista.

5 Durante el período 1920-1946 existieron numerosos órganos de difusión de la producción humanística en la FHyCE. La revista Humanidades, fundada en 1920 por Ricardo Levene, estaba destinada a la publicación de artículos inéditos de las tres secciones: filosofía y ciencias de la educación, historia y letras. Asimismo, a partir de 1923, comenzó a editarse la colección de libros "Biblioteca de Humanidades" dedicada a la publicación de obras de profesores de las tres secciones. Por su parte, las consideradas mejores monografías de los estudiantes, realizadas en el marco de los cursos de seminario y lectura y comentario de textos, eran publicadas en Cuadernos. El Anuario Bibliográfico y los Cuadernos de temas para la escuela primaria completaban el espectro de publicaciones de la FHyCE. Entre 1921 y 1946, en la revista Humanidades, la mayoría de las publicaciones fueron dedicadas al área de Historia con 163 artículos, seguida por Letras con 104, Filosofía con 61 y Educación con 57 (Zarrilli, Gutiérrez y Graciano, 1998, p. 208). Las publicaciones filosóficas se concentraron en el período 1921-1930 y fueron los profesores Tomás Casares, Enrique Mouchet y Alfredo Franceschi quienes mayor número de artículos publicaron. Más parejas fueron las publicaciones dedicadas a las monografías de los estudiantes: de los 10 trabajos de seminario, cursos de lectura y comentario de textos y clases prácticas que fueron publicados, dos correspondieron a filosofía, dos a historia, dos a letras y cuatro a ciencias de la educación (Ruvituso, 2008).

6 En su historia de la Facultad de Filosofía y Letras de la UBA, Pablo Buchbinder señala esta característica: "La enseñanza de la filosofía en la Facultad se caracterizó, en sus inicios, por la impronta claramente positivista que le imprimieron los primeros titulares de las materias del área. Estos eran por lo general médicos y abogados y su interés por los problemas filosóficos se relacionaba, en muchos casos, con sus intereses profesionales específicos, aproximándose a las cuestiones filosóficas en tanto presupuestos para la práctica de otro tipo de actividades" (1997, p. 59).

7 Hemos podido establecer que Ernesto Figueroa, Luis Juan Guerrero, José Antonio Rodríguez Cometta, Francisco Maffei, Eugenio Pucciarelli y Emilio Estiú pertenecieron a diferentes promociones del Colegio Nacional de La Plata.

8 Compuesto por Alberto Rougés, Juan B.Terán, José Padilla, Emiliano Cross, Ricardo Jaime Freyre, Miguel Lillo, Juan Heller, entre otros.

9 Resolución $\mathrm{N}^{\circ}$ 296-80-939 del 3 de agosto de 1939.

10 Para la reconstrucción de los grupos académicos que formaron la FFyL tucumana hemos utilizado datos disponibles en Vanella (2008), Nader (1999), Garrido Biazzo (1999), Naesens y Santillán (1999) y Suayter Monetti (2004).

11 El "Seminario de Filosofía" corresponde al Doctorado en Filosofía.

12 Se ausentó por un viaje de estudios a EE.UU. entre 1942 y 1943.

13 Manuel García Morente regresó a España en 1938. Tenía razones para no estar totalmente a gusto en Tucumán. Los estudios humanísticos se encontraban en formación, de modo que no había bibliotecas especializadas ni un plantel docente constituido que le permitiera un intercambio fluido. Si bien su renuncia fue "por motivos personales", la correspondencia con Ortega y Gasset pone de relieve su descontento respecto de los escasos recursos locales para el desarrollo intelectual.

14 Además de dar clases de idioma en las carreras de Filosofía y Pedagogía y de Filosofía y Letras, Hamelka se desempeñó en la carrera de Idiomas, en los cargos de "Ejercicio de idioma Francés III” y "Latín III". En 1940 reemplazó a Elsa Tabering en "Historia de la lengua francesa" y en "Historia francesa I y II".

15 La asignatura "Sociología" se encuentra incluida en los planes de estudio desde 1946, ya que se incorpora como materia optativa respecto de "Historia argentina del siglo XIX".

16 En el desarrollo editorial, el espacio disciplinar más abierto lo sostuvieron las figuras locales, mientras que los profesores rioplatenses intentaban llevar a cabo proyectos de publicación específicamente filosóficos. Es probable que incluso sus actores no fueran conscientes del nivel de especialización que iba tomando el trabajo editorial, entre 1939 y 1949 . En el interior de la Facultad, se editó la primera serie de Cuadernos de Filosofía entre 1942 y 1956, con un claro perfil filosófico; aparecieron, también proyectos editoriales independientes como Yerba Buena entre 1944 y 1946 que -aunque tenían un sesgo interdisciplinar- contaban con buena cantidad de publicaciones sobre filosofía. 
17 Alberini renunció a la cátedra de "Introducción a la Filosofía", para jubilarse en 1946. Se encontraba gravemente enfermo. Su última participación pública se dio en el marco del Primer Congreso Nacional de Filosofía de 1949. Para la trayectoria de Alberini ver Pró (1960).

18 Los datos de cesantías y renuncias fueron extraídos del archivo "Resoluciones del Decano" de la UNLP.

19 Como podemos advertir, los originales posicionamientos frente a la Reforma, de parte de muchos profesores, no permanecieron a lo largo del tiempo, y se fueron modificando. Alberini, Astrada, Guerrero y Maffei, quienes se desempeñaron en la vida académica durante el peronismo, compartían estrechos lazos de amistad desde 1920 y habían ido desarrollando posturas ideológicas comunes (Ruvituso, 2015). Guillermo David dio cuenta de este cambio de posicionamiento frente a la Reforma al interior de este grupo, que compartía lo que denominó una "tercera posición”, según la cual la "nueva Universidad", surgida de 1918, se entendía "alienada" en una mera "retórica de la acción política”; si bien se criticaba la vieja Universidad aristocrática, también se rescataba su "tolerancia y civismo" (2004, p. 72).

20 En 1943 el delegado interventor Santiago de Estrada exoneró de sus cargos a Hamelka, Dargan, Terracini, Treves y Rush, desencadenando la renuncia de Luzuriaga, Pucciarelli y Navarro. Treves, Rush y Terracini fueron reincorporados durante la intervención de Sánchez Reulet en 1944 (es decir, tres meses más tarde), mientras que Dargan, Hamelka Luzuriaga, Pucciarelli y Navarro se retiraron definitivamente de sus cargos.

21 Durante el período 1946-1947, se produjeron leves cambios en los planes de estudio. Por un lado, el profesorado de Filosofía y Pedagogía dejó de contar con "Psicología pedagógica", y en su lugar se incluyó una materia optativa. Asimismo, "Historia argentina del siglo XIX" tomó carácter opcional, pudiéndose elegir, en su lugar, "Sociología" o "Historia de las ciencias". Además, se incluyó en la formación de idiomas modernos la lengua italiana, y se agregó un curso más de idioma moderno en tercer año. A partir de 1948 se aplicó un nuevo plan de estudios, propuesto por Roger Labrousse y Juan A. Vázquez y alentado por Guido Parpanoli. Durante este período, la carrera de Filosofía y Letras pasó a llamarse "Licenciatura en Filosofía". El plan contó con un ciclo básico, dividido en dos partes: por una parte, "Historia de la cultura", "Evolución histórica”, "Evolución del pensamiento” y "Literatura", y por otra parte, "Lenguas", "Lengua Castellana e Idioma Moderno I”, y un ciclo superior que contó con cuatro grupos: en el Grupo I se encontraba "Psicología”, "Lógica”, “Gnoseología y Metafísica”, "Ética”, "Estética” y "Sociología”; en el Grupo II se podía elegir entre "Ciencias exactas", "Ciencias naturales” y "Ciencias históricas”; en el Grupo III se encontraban "Idiomas Modernos” y "Lenguas Clásicas”, y en el Grupo IV "Estudios y trabajos prácticos” (en asignaturas del Grupo I) y "Seminario como adscripto” (para materias del Grupo I). Este plan de estudios se inspiró en el Saint John’s College de Annapolis, Maryland (Schobinger, 1995). En cuanto al Profesorado en Pedagogía y Filosofía, se mantuvo idéntico al plan de 1946-1947, excepto por la eliminación de "Literatura argentina y americana", y la inclusión de "Didáctica general" y de una materia optativa en el último año.

22 A través del Secretario Militar de la Presidencia de la Nación Coronel Julio Silva.

23 Junto con estos profesores, fueron exonerados María Elena Saleme (de “Idiomas modernos") y Juan José Arévalo (de "Literatura"). En su lugar, ingresó el lingüista italiano Giovanni Turín, que se desempeñó entre 1947 y 1951 en "Lengua y literatura italiana".

24 La muerte de Augusta Algranatti, su esposa y colaboradora, lo llevó a desplazarse a Buenos Aires, para rencontrarse con sus dos hijos, Ugo y Silvano Mondolfo.

25 Formado en Instituto de Humanidades de la Inmaculada Concepción.

26 Además, Pró fundó la revista Humanitas, que constituye el primer intento de historizar la filosofía en Argentina, tomando en consideración especialmente al grupo de profesores que rodearon a Coriolano Alberini en el Primer Congreso Nacional de Filosofía, en 1949.

27 Estos profesores, además, participaron de los cursos del Instituto Santo Tomás de Aquino, fundado en 1949 por sacerdotes del convento Santo Domingo, y dirigido por el Fr. Alberto Quijano, dictando clases e invitando a profesores como Octavio N. Derisi, Nimio de Anquín y los europeos Michele Federico Sciacca y Régis Jolive (Vázquez, 1965). Hacia mediados de 1960, el Instituto Universitario Santo Tomás de Aquino se convirtió en la Universidad del Norte Santo Tomás de Aquino. 